\title{
Changes in survival of colorectal cancer patients in Świętokrzyskie Province (Southern Poland) from the second half of the 1990s to the early 21st century - a population-based study
}

\author{
Paweł Macek ${ }^{1,2, A-D, F} \oplus$, Małgorzata Biskup ${ }^{3,4, B-C \oplus}$, Przemysław Ciepiela ${ }^{5, B, E \oplus}$, \\ Małgorzata Terek-Derszniak ${ }^{3, C-D \oplus}$, Barbara Sosnowska-Pasiarska ${ }^{6, D}{ }^{\oplus}$, Halina Król ${ }^{4, E-F}$, \\ Jolanta Smok-Kalwat ${ }^{7, E}{ }^{\oplus}$, Stanisław Góźdźn ${ }^{7,4, A, E-F}$ \\ ${ }^{1}$ Department of Epidemiology and Cancer Control, Holy Cross Cancer Center, Poland \\ ${ }^{2}$ Faculty of Medical Sciences, School of Economics, Law and Medical Sciences, Poland \\ ${ }^{3}$ Department of Rehabilitation, Holy Cross Cancer Center, Poland \\ ${ }^{4}$ Faculty of Medicine and Health Sciences, Jan Kochanowski University, Poland \\ ${ }^{5}$ Surgical Oncology Clinic, Holy Cross Cancer Center, Poland \\ ${ }^{6}$ Department of Oncocardiology, Holy Cross Cancer Center Poland \\ ${ }^{7}$ Clinical Oncology Clinic, Holy Cross Cancer Center Poland \\ A - Research concept and design, B - Collection and/or assembly of data, C - Data analysis and interpretation, \\ $D$ - Writing the article, $E$ - Critical revision of the article, $F$ - Final approval of article
}

Macek P, Biskup M, Ciepiela P, Terek-Derszniak M, Sosnowska-Pasiarska B, Król H, Smok-Kalwat J, Góźdź S. Changes in survival of colorectal cancer patients in Świętokrzyskie Province (Southern Poland) from the second half of the 1990s to the early 21 st century - a populationbased study. Ann Agric Environ Med. 2020; 27(2): 301-305. doi: 10.26444/aaem/106042

\section{Abstract}

Introduction and objectives. For years, the increase in cancer incidence and deaths has constituted a significant health and social problem. Variation in the burden in cancers in different regions of the world requires constant monitoring of the epidemiological situation in this regard. Assessing survival in cancer patients is a valuable source of information for patients and physicians alike, as well as for politicians who have a direct impact on the shaping of health policy and health systems. The aim of the present study was to assess the changes in the 5-year relative survival of colorectal cancer patients during 1995-2014.

Materials and method. The data of 8,970 patients with colorectal cancer in the years 1995-2014, 5,033 males and 3,937 females aged $67.5 \pm 11.7$ from Świętokrzyskie Cancer Registry were used. Cases were classified according to the topographical codes ICD-O-3: C18.0-C18.9, C19.9, C20.9, C21.0-C21.2, C21.8. The end of follow-up was fixed at 31 December 2014. Four five-year calendar periods were defined. In each calendar period, relative survival rates using the Ederer II method were estimated separately for males and females.

Results. In 2010-2014 (against 1995-1999), the absolute increase in the 5-year relative survival in males and females with colon cancer was the highest and reached 9.8 percentage point (p.p.) and 9.6 p.p., respectively. Patterns of survival for both colon and rectal cancer patients according to gender and age were very similar.

Conclusions. In 1995-2014, an increase in the value of relative survival rates of males and females with colorectal cancer was observed. Systematic increase in funding in health care was a chance for reducing the burden of colorectal cancer by more widespread and equal access of effective early detection and cancer treatment.

Key words

colorectal cancer, relative survival, population-based registries

\section{INTRODUCTION}

Colorectal cancer is one of the most common cancers in the world. Each year, more than 1.3 million new cases and 700,000 colorectal cancer deaths are recorded. More than half of the cases concerns the well-developed countries whereas every second death is recorded in underdeveloped countries. Incidence and mortality in different regions of the world are characterized by great geographic variation. In both genders, incidence patterns indicate greater geographical variation compared with mortality patterns [1].

Address for correspondence: Paweł Macek, Department of Epidemiology and Cancer Control, Holy Cross Cancer Center, Poland

E-mail: pawel.macek@gazeta.pl

Received: 03.12.2018; accepted: 25.03.2019; first published: 09.04.2019
In 2012 in the European Union member states, more than 340,000 new cases and 150,000 colorectal cancer deaths were recorded. A high incidence in males was observed in the countries of Central and Northern Europe and in females in Western European countries. The lowest incidence was observed in the south of Europe. Geographic mortality patterns were partially overlapped by incidence patterns; however, in some countries of Central and Eastern Europe, relatively high mortality rates was observed together with low incidence rates [2].

In 2014 in Poland, more than 18,000 new cases and 11,000 colorectal cancer deaths were observed. Within the structure of cancer incidence, the colorectal cancer occupied third place in males and second in females. As for the structure of cancer deaths, colorectal cancer occupied the second position in males and the third in females [3]. 
Development in both incidence and death from colorectal cancer more frequently affects males than females. Over $90 \%$ of cases are observed in patients over 50 years of age [4]. Apart from gender, the main colorectal cancer risk factors include environmental, dietary, genetic and family factors $[5,6]$. The symptoms of colorectal cancer in its early stages are often non-specific. Depending on the site of the cancer, there are some disorders of the gastrointestinal tract, weight loss, discomfort or abdominal pain $[7,8,9]$. Since 2000 in Poland, the Screening Programme for Colorectal Cancer has been conducted, aimed at males and females aged 50-65 and at people aged $40-65$ with a positive family history.

\section{OBJECTIVES}

The main aim of this study was to assess the dynamics and trends in changes in the 5-year relative survival in males and females with colorectal cancer in 1995 - 2014.

\section{MATERIALS AND METHOD}

Data Sources. The study used the data regarding colorectal cancer incidence and deaths in the Świętokrzyskie Province of Southern Poland, in the years 1995-2014, according to gender collected from the Cancer Registry (CR) at the Holy Cross Cancer Center. The data at the CR was collected on the basis of the Act of 29 June 1995 on public statistics (Journal of Laws, No. 88 item 439, as amended). Life tables for 1995-2014 by age, gender and calendar year were obtained from the Information Portal of the Central Statistical Office in Poland.

Material. Initial screening included 10,172 cases $(5,620$ males and 4,552 females) of colorectal cancer in the Świętokrzyskie Province in 1995-2014. The cases of colon, rectosigmoid junction, rectum, anus and rectal canal cancers were qualified according to topographical codes of International Classification of Diseases for Oncology $\left(3^{\text {rd }}\right.$. edn.), ICD-O-3: C18.0-C18.9, C19.9, C20.9, C21.0-C21.2, and $\mathrm{C} 21.8$, respectively. The behaviour of the tumour was based on morphological codes ICD-O-3.

Data Verification. In the first stage of verification, all cases of malignant tumours in situ, as well as benign tumours, tumours of uncertain behaviour (malignant or benign), metastatic to the colon or/and rectum from elsewhere, malignant lesion, uncertain whether primary or metastatic site, and all the cases in patients under the age of 15 and above 99, were removed from the database.

In the second stage of verification, all cases known to registries by death certificate only (DCO) and detected accidentally at autopsy, cases with undetermined life status, age, gender or wrong sequence of dates (e.g. the date of death prior to the date of diagnosis), or inconsistency of tumour site and morphology, age and tumour site, age and morphology, as well as age, tumour site and morphology were also removed from the database. As a result, the statistical analysis included 8,970 patients (5,033 males and 3,937 females) (Tab. 1).

The proportion of microscopic verification (MV), proportion of non-specific morphology (NM) 8000-8005 according to morphological codes ICD-O-3, and the proportion of cases lost to observation and censored cases of the patients diagnosed in the years 1995-2009 with the observation period shorter than 5 years, were used as indicators of data quality (1995-2014).

Statistical analysis. Analysis included the data on colorectal incidence and deaths in the Swiętokrzyskie Province in 1995-2014, according to gender. The end of follow-up was fixed at 31 December 2014. Four five-year calendar periods were defined. In each calendar period, relative survival rates were estimated separately for males and females (Fig. 1).

Patients diagnosed in 1995-1999, 2000-1004 and 20051009 , reported a minimum 5 -year observation period until the end of 2014. The probability of survival for patients diagnosed in these 3 calendar periods was estimated applying the classical cohort fashion [10, 11]. In 2010-2014, a full 5 -year observation period was possibly only for the patients diagnosed in 2010. In the remaining years, the observation lasted from $1-4$ years. Therefore, in order to estimate the probability of survival the period estimate was applied.

Periodic estimation of survival was obtained by multiplying the conditional probabilities of survival during each calendar year for the patients diagnosed with colon or rectal cancer in 2005-2014 [10, 11]. The probability of observed survival was estimated using the actuarial method, whereas expected survival was measured by means of the Ederer II method. The confidence interval for the relative survival function was calculated assuming that the estimate is of normal distribution around the true value, with the estimated variation obtained by the square of the standard error [12].

Table 1. Quality of data for colorectal cancer cases 1995-2014

\begin{tabular}{|c|c|c|c|c|c|c|c|c|c|c|}
\hline Calendar & No. of cases & Males & Age $\geq 75$ & Rectum & MV & NM & DCO & Autopsy & Other & $\begin{array}{l}\text { Lost to } \\
\text { follow-up }\end{array}$ \\
\hline & & (\%) & (\%) & (\%) & (\%) & (\%) & (\%) & (\%) & (\%) & (\%) \\
\hline 1995-1999 & 1756 & 52.8 & 28.0 & 43.2 & 79.2 & 0.7 & 4.2 & 0.2 & 30.0 & 0.0 \\
\hline 2000-2004 & 2483 & 54.7 & 30.4 & 43.2 & 85.8 & 0.5 & 2.7 & 0.0 & 21.0 & 0.0 \\
\hline 2005-2009 & 2781 & 54.5 & 34.3 & 39.2 & 91.2 & 1.0 & 2.2 & 0.0 & 13.1 & 0.0 \\
\hline 2010-2014 & 3152 & 57.7 & 35.2 & 36.5 & 95.3 & 0.6 & 1.0 & 0.1 & 6.6 & 0.0 \\
\hline 1995-2014 & 10172 & 55.2 & 32.6 & 40.0 & 89.1 & 0.7 & 2.3 & 0.1 & 15.9 & 0.0 \\
\hline
\end{tabular}

MV - microscopic verification; NM - non-specific morphology; DCO - death certificate only 


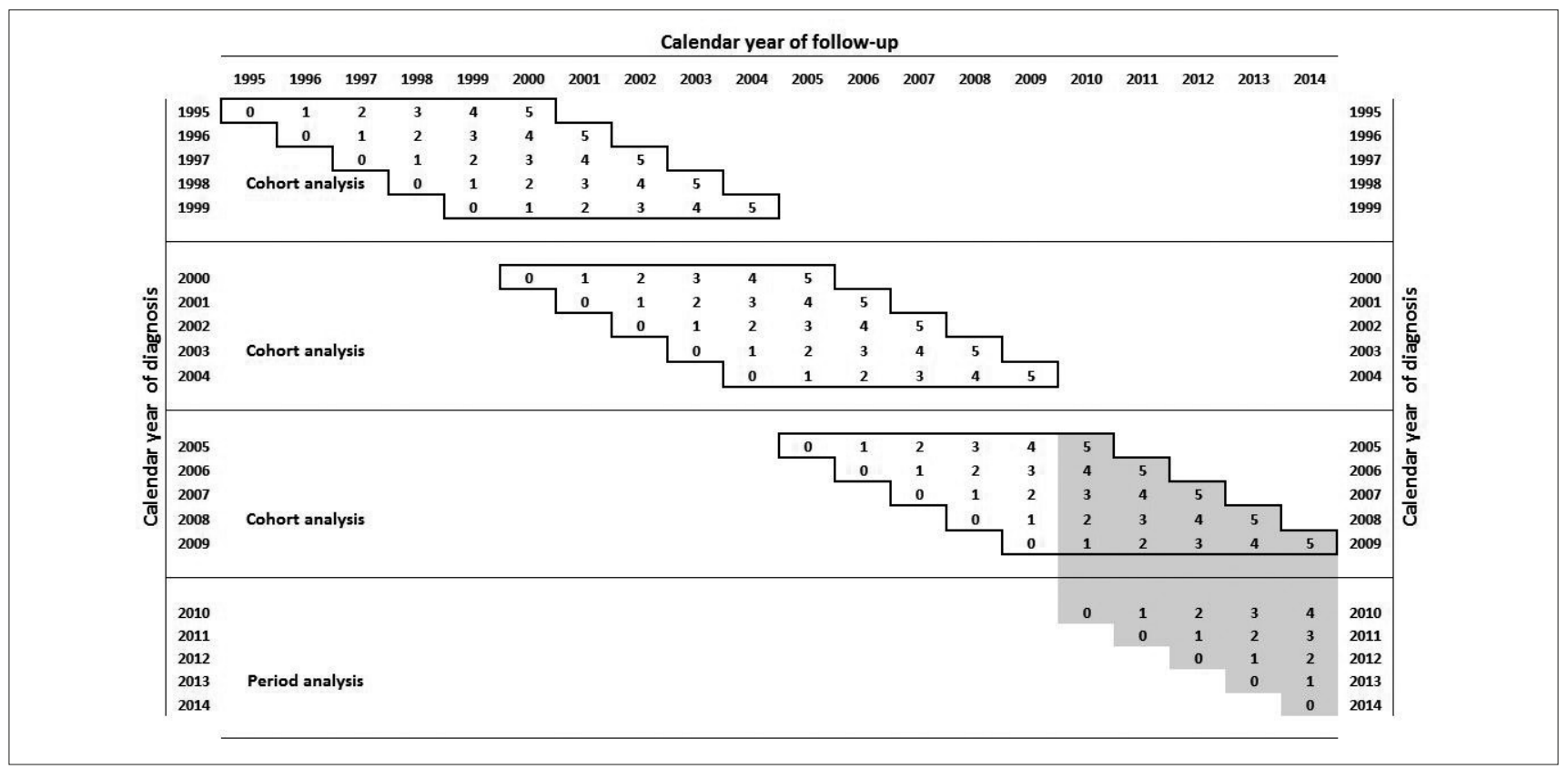

Figure 1. Structure of survival analysis of patients diagnosed with colorectal cancer in $1995-2014$, taking into account the number of years of complete follow-up on the basis of the date of diagnosis and the date of the end of the observation

The standardization of 5-year relative survival rates was conducted by means of the direct method. The function of relative survival standardized according to age is defined as the weighted average for the accumulated relative survival functions specific for age groups. The weights are proportions of patients in each age group for the population adopted as a standard at the beginning of the observation period [13, 14]. All statistical analyses were completed using the SAS version 7.1.

\section{RESULTS}

Based on the observation of the estimated relative survival of patients with colorectal cancer in the Świętokrzyskie Province of Southern Poland in 1995-2014, a diverse range of growth in their values in successive 5-year calendar periods, depending on the cancer location and gender, was observed. Regardless of the location of the tumour, the higher absolute increase in survival rates affected males than females. With regard to the reference period (1995-1999), the highest absolute increase in the 5-year survival rates in males with colon cancer was observed in 2010-2014 (9.8 p.p.). Improved survival in males with colon cancer in the 2000-2004 and 2005-2009 amounted to 4.5 p.p. and 4.0 p.p., respectively. Similarly, in females, the greatest absolute increase in the 5-year survival indicator was observed in 2010-2014 (9.6 p.p.). The increase in survival in females with colon cancer in 2000-2004 was small and amounted to 0.3 p.p. In the subsequent five-year calendar period, the increase in survival in females with colon cancer reached 2.3 p.p., and was almost twice as low as males (Tab. 2).

The patterns in improved survival in patients with rectal cancer in both genders were characterized by an upward trend, but with higher dynamics of changes than in patients with colon cancer. In 2010-2014 (vs. 1995-1999), the absolute increase in the 5-year survival rates in males with rectal cancer was the highest and reached 15.4 p.p. In the earlier calendar periods of 2000-2004 and 2005-2009, the increase in survival was twice lower and reached 6.5 p.p. and 7.9

Table 2. 5-year relative survival by period of diagnosis 1995-2014

\begin{tabular}{|c|c|c|c|c|c|c|c|c|}
\hline \multirow{3}{*}{$\begin{array}{c}\text { Calendar } \\
\text { period }\end{array}$} & \multicolumn{3}{|c|}{ Males } & \multirow{3}{*}{$\begin{array}{l}\text { Absolute } \\
\text { difference }\end{array}$} & \multicolumn{3}{|c|}{ Females } & \multirow{3}{*}{$\begin{array}{l}\text { Absolute } \\
\text { difference }\end{array}$} \\
\hline & Cases & Survival & \multirow{2}{*}{$95 \% \mathrm{Cl}$} & & Cases & Survival & \multirow{2}{*}{$95 \% \mathrm{Cl}$} & \\
\hline & No. & $\%$ & & & No. & $\%$ & & \\
\hline \multicolumn{9}{|c|}{ Colon cancer } \\
\hline 1995-1999 & 394 & 45.3 & $(32.0-58.8)$ & - & 358 & 49.4 & $(36.1-62.1)$ & - \\
\hline 2000-2004 & 620 & 49.8 & $(38.8-60.4)$ & 4.5 & 540 & 49.7 & (38.9-60.0) & 0.3 \\
\hline 2010-2014 & 1059 & 55.1 & $(45.8-64.0)$ & 9.8 & 832 & 59.0 & $(49.5-67.2)$ & 9.6 \\
\hline \multicolumn{9}{|c|}{ Rectal cancer } \\
\hline 1995-1999 & 353 & 37.6 & $(24.9-51.3)$ & - & 271 & 41.3 & $(27.2-55.3)$ & - \\
\hline 2000-2004 & 558 & 44.0 & $(33.2-55.1)$ & 6.5 & 395 & 46.9 & $(34.8-58.2)$ & 5.5 \\
\hline 2005-2009 & 583 & 45.5 & $(34.7-56.5)$ & 7.9 & 423 & 50.6 & $(38.0-62.2)$ & 9.3 \\
\hline
\end{tabular}


p.p., respectively. In 2005-2009 and 2010-2014, the absolute increase in survival in females with rectal cancer was similar and reached 9.3 p.p. and 9.4 p.p., respectively. In 2000-2004, the increase in the 5 -year survival rates in females was slightly lower than in males and amounted to 5.5 p.p.

Regarding age, the patterns of survival in males and females with colon cancer were very similar, except for 2000-2004, when a generally higher survival was observed in females than in males. Since 2005, the higher values in survival rates were observed in males over the age of 75 . The highest absolute increase in survival was reported in middle-aged and older males (10.8 p.p. - 18.5 p.p.), as well as young and middle-aged females (21.7 p.p. - 23.1 p.p.). In the group of males under the age of 54 , a decrease in survival rate was reported -6.6 p.p.- 10.2 p.p.. The highest growth in survival was observed in both gender over the age of 55 .

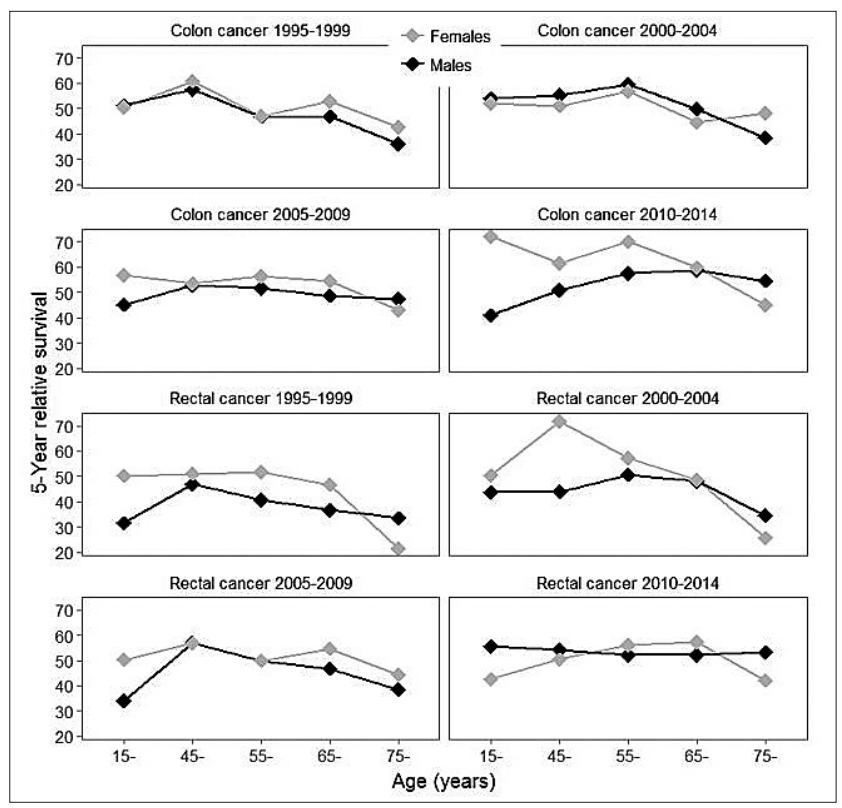

Figure 2. Five-year relative survival by age for colon and rectal cancers 1995-2014

Until 2009, the growth in five-year relative survival in patients with rectal cancer in all analysed age groups was higher in females than in males. In 2010-2014, higher survival was observed in females aged 55-74. The highest absolute increase in survival rates concerned males and females over the age of 60, as well as males aged 15-44. In the group of females under the age of 54 , a decrease in the survival rate was observed (0.5 p.p. - 7.8 p.p.). In the entire period of analysis, a greater survival growth was observed in males than in females (Fig. 2).

\section{DISCUSSION}

For years, the increase in cancer incidence and deaths has constituted a significant health and social problem. The variation in the burden of cancers in different regions of the world requires constant monitoring of the epidemiological situation in this regard. Assessing survival in cancer patients is a valuable source of information not only for patients and physicians, but also for politicians who have a direct impact on the shaping of health policy and health systems [15]. The relative survival rate is estimated as the ratio of survival observed in a group of patients with a given disease in a given period of time, taking into account all causes of death in this group and expected survival, which is the probability of survival of the population similar to the analysed group of patients by age, gender and the calendar year of survival [16].

In epidemiological studies, the assessment of survival is carried out for patients with the most common cancers and the cancers in particular sites or all cancers combined. The survival of colorectal cancer patients is a common subject of epidemiological studies, conditioned by high incidence and mortality in Europe worldwide.

Differences in survival depend mainly on clinical conditions at the time of diagnosis and the application of different diagnostic and therapeutic methods [17, 18]. Other factors likely to affect the life expectancy of patients with colorectal cancer are also frequently analysed. The most frequently mentioned factor includes age at the time of diagnosis. The relative increase in the risk of death in patients over the age of 75 is sometimes $50 \%$ higher compared to patients aged 15-44 [19]. The survival of patients is also related to the GDP and total health care expenditure [20].

The participation of a target population in secondary prevention programmes should have a significant impact on improving survival. In Poland, the Screening Programme for Colorectal Cancer has been implemented since 2000. In 2012-2015, the value of implemented procedures amounted to over 19 million EURO, with the funds coming from the State budget. In 2015, in comparison with 2012, the funds allocated for the implementation of the programme nearly doubled. The number of patients who underwent screening increased by $72 \%$, whereas the number of people diagnosed with colorectal cancer increased by $17 \%$. In 2014 , the percentage of diagnoses of colorectal cancer in the early stages of the disease was $46.5 \%$, which was $8.5 \%$ higher than in 2005. Despite the increase in funding, the percentage of people participating in the programme was very low and amounted to $16.8 \%$ of the target group [21].

In the current study, a diverse range of relative survival of patients with colon cancer by calendar period and age was reported. In general, the estimated values of the 5-year relative survival were higher for females, compared to males. Only in 2010-2014, the survival rate of males with rectal cancer was slightly higher than for females. Both in the case of colon and rectal cancers, a greater absolute increase in survival probability concerned males rather than females. A similar mechanism of increased growth in survival in a part of the population was observed in other studies [22]. It consisted in a significant improvement in the relative values of survival in cohorts of patients in which in previous periods or studies their low values were reported. Behaviour changes in society in terms of cancer prevention and steady increase in the access to guaranteed health care benefits, will equalize the survival of various subpopulations to a level where it will be possible in a given area due to the existing social and health conditions. Compared to the period 1995-1999, the largest increase in the survival rates in males was recorded in 2010-2014. The patterns of 5-year relative survival in the age groups varied, depending on gender and calendar period. A higher probability of 5-year survival after the diagnosis of patients with colon cancer related to middle-aged and older males, as well as young and middle-aged females. In the case of rectal cancer patients, the highest probability of survival was reported in middle-aged males and females. The low 
survival rate of females over the age of 75 was observed in 1995-2004. After this period, the relative survival of females with rectal cancer greatly improved. Regardless of age, the greater probability of survival was related to males, compared to females.

Monitoring the survival of cancer patients in the Swiętokrzyskie Province is required. The observation should be conducted not only for patients with colorectal cancer but for all cancer patients, both those that occur most frequently, as well as those occurring less frequently. The current assessment of the region's population cancer burden should result in comprehensive actions in the field of current health policy in the region, both in terms of diagnostic and therapeutic procedures, as well as important preventive actions in the form of primary prevention, aimed at early detection of disease, secondary prevention, and tertiary prevention which guarantee patients easy access to guaranteed health care benefits.

\section{CONCLUSIONS}

In 1995-2014 in the Świętokrzyskie Provincve of Southern Poland, an increase in the value of relative survival rates of males and females with colorectal cancer was observed. In all the analysed calendar periods, the patterns of relative survival in both genders were very similar. Regardless of age and survival time, a higher growth in the probability of survival related to males compared to females. Documented systematic increase in funding in health care was a chance for reducing the burden of colorectal cancer by more widespread and equal access of effective early detection and cancer treatment.

\section{Conflict of interests}

The authors report no conflict of interest whatsoever with regard to the present study.

\section{Ethics approval and informed consent}

The study used data routinely collected in the Cancer Registry of the Holycross Cancer Center in Kielce. During the processing of epidemiological data, the authors complied with the provisions of the Act on Personal Data Protection (Journal of Laws, 2016. item 922).

\section{Funding}

The study was financed from the authors' own funds.

\section{REFERENCES}

1. Fact Sheets by Cancer. http://globocan.iarc.fr/Pages/fact_sheets_ cancer.aspx (access 2017.05.25).

2. Ferlay J, Steliarova-Foucher E, Lortet-Tieulent J, Rosso S, Coebergh JWW, Comber $\mathrm{H}$, et al. Cancer incidence and mortality patterns in Europe: Estimates for 40 countries in 2012. Eur J Cancer. 2013; 49(6):1374-403. https://doi: 10.1016/j.ejca.2012.12.027.
3. Wojciechowska U, Olasek P, Czauderna K, Didkowska J. Nowotwory złośliwe w Polsce [Cancer in Poland in 2014] w 2014 roku. Krajowy Rejestr Nowotworów; 2016 in Polish.

4. Korniluk J, Wcisło G, Nurzyński P, Stec R, Bodnar L, Obrocka B, et al. Epidemiology of colorectal cancer. Contemp Oncol Onkol. 2006; 10(3). https://www.termedia.pl/Epidemiology-of-colorectalcancer, 3,5861,1,1.html (access 2006.04.12).

5. Boyle T, Fritschi L, Platell C, Heyworth J. Lifestyle factors associated with survival after colorectal cancer diagnosis. Br J Cancer. 2013; 109(3):814-22. https://doi: 10.1038/bjc.2013.310.

6. Kubiak A, Kycler W, Trojanowski M. Epidemiologia i profilaktyka raka jelita grubego w Polsce [Epidemiology and prevention of colorectal cancer in Poland]. Probl Hig Epidemiol. 2014; 95(3):636-42 in Polish.

7. Krzakowski M, Warzocha K, Wysocki P. Onkologia kliniczna. T. II [Clinical Oncology. Vol. II]. Gdańsk: VIA MEDICA, 2015 in Polish.

8. Pazdur R, Wagman L, Camphausen K, Hoskins W. Nowotwory złośliwe Postępowanie wielodyscyplinarne Leczenie systemowe, chirurgia, radioterapia. T. 1 [Cancers Multidisciplinary Systemic treatment, surgery, radiotherapy Vol. 1]. Lublin: CZELEJ Sp.z.o.o, 2012 in Polish.

9. Jassem J, Krzakowski M. Nowotwory układu pokarmowego Praktyczny przewodnik dla lekarzy [Cancer of the digestive system Practical guide for physicians]. Gdańsk, VM Media, 2014 in Polish.

10. Brenner $\mathrm{H}$, Hakulinen T. Period versus cohort modeling of up-to-date cancer survival. Int J Cancer. 2008; 122(4):898-904.

11. Jansen L, Hakulinen T, Brenner H. Study populations for period analyses of cancer survival. Br J Cancer. 2013; 108(3):699-707. https:// doi: [10.1038/bjc.2013.14].

12. Dickman P. Estimating and modelling relative survival using SAS http://www.pauldickman.com/rsmodel/(access 2016.12.27).

13. Pokhrel A. Age-Standarization of Relative Survival Ratios for Cancer Patients. Academic Dissertation. University of Tampere, 2007.

14. Age Standards for Survival - SEER Datasets. https://seer.cancer.gov/ stdpopulations/survival.html (access 2017.05.22).

15. Allemani C, Weir HK, Carreira H, Harewood R, Spika D, Wang X-S, et al. Global surveillance of cancer survival 1995-2009: analysis of individual data for 25676887 patients from 279 population-based registries in 67 countries (CONCORD-2). The Lancet. 2015; 385(9972):977-1010. https://doi: 10.1016/S0140-6736(14)62038-9.

16. Cho H, Howlader N, Mariotto AB, Cronin KA. Estimating relative survival for cancer patients from the SEER Program using expected rates based on Ederer I versus Ederer II method. https://surveillance. cancer.gov/reports/ (access 2017.05.1).

17. Gatta G, Capocaccia R, Sant M, Bell CMJ, Coebergh JWW, Damhuis R a. $\mathrm{M}$, et al. Understanding variations in survival for colorectal cancer in Europe: a EUROCARE high resolution study. Gut. 2000; 47(4):533-8. https://doi: 10.1136/gut.47.4.533.

18. Ciccolallo L, Capocaccia R, Coleman MP, Berrino F, Coebergh JWW, Damhuis RAM, et al. Survival differences between European and US patients with colorectal cancer: role of stage at diagnosis and surgery. Gut. 2005; 54(2):268-73. https://doi: [10.1136/gut.2004.044214].

19. Gatta G, Faivre J, Capocaccia R, Leon MP de. Survival of colorectal cancer patients in Europe during the period 1978-1989. Eur J Cancer. 1998; 34(14):2176-83. https://doi: [10.1136/gut.47.4.533].

20. Baili P, Salvo FD, Marcos-Gragera R, Siesling S, Mallone S, Santaquilani $\mathrm{M}$, et al. Age and case mix-standardised survival for all cancer patients in Europe 1999-2007: Results of EUROCARE-5, a population-based study. Eur J Cancer. 2015; 51(15):2120-9. https://doi: 10.1016/j. ejca.2015.07.025.

21. NIK o profilaktyce zdrowotnej w systemie ochrony zdrowia - Najwyższa Izba Kontroli [NIK on health prevention in the health care system Supreme Chamber of Control] https:/www.nik.gov.pl/aktualnosci/ nik-o-profilaktyce-zdrowotnej-w-systemie-ochrony-zdrowia.html (access 2018.01.25) in Polish.

22. Verdecchia A, Guzzinati S, Francisci S, Angelis RD, Bray F, Allemani C, et al. Survival trends in European cancer patients diagnosed from 1988 to 1999. Eur J Cancer. 2009; 45(6):1042-66. https://doi: 10.1016/j. ejca.2008.11.029. 